\title{
Mercè Rodoreda i María Teresa León: dos exilis i dues literatures amb veu de dona
}

Isabel Marcillas Piquer

Universitat d'Alacant

Va ser al llarg de la segona meitat del segle XIX que la inserció de la dona de classe mitjana en la vida laboral començà a considerar-se com una tasca inajornable. Les dones espanyoles havien desenvolupat fins aquells moments el rol d'àngels de la llar; les seues preteses qualitats morals i l'abnegació de què feien mostra les havien convertides en l'estendard de la societat burgesa, cosa que les feia romandre en una lamentable situació d'indigència cultural, una situació que havia d’anar canviant de manera progressiva al llarg de les dècades següents amb l'ajut dels moviments feministes. Aquesta circumstància propicià que el paper de la dona com a consumidora de literatura prenguera rellevància. Tot i que els índex analfabetisme entre el sexe femení eren encara ben elevats, a poc a poc, la dona s’erigia, no solament com a públic lector sinó també com a productora literària. En aquest sentit, però, també l'escriptura de dona havia estat sovint menystinguda davant de la de l'home; l'adjectiu femení que duia implícit aquesta escriptura, li suposava de bestreta una sèrie d'atributs que sovint eren aquells que la societat patriarcal havia assignat $\mathrm{i}$ assumit com a propis i innats de les dones i, gairebé sempre, relacionats amb un cert sentimentalisme carrincló.

Però, malgrat el menys teniment de què sovint foren objecte, les dones no solament sabien fer literatura, sinó bona literatura. ${ }^{1}$ D’aquí l’objectiu d'aquestes pàgines, comparar l'escriptura de dues dones coetànies, María Teresa León i Mercè Rodoreda, que, entre d'altres coses, tenen en comú el fet d'haver tingut un pes rellevant en el panorama de la literatura que cadascuna representa. De María Teresa León, nascuda a Logroño el 1903 es diu que va destacar per mèrits propis, com a lluitadora infatigable i com a excel-lent femme de lettres, tot i que en parlar d'ella resulta impossible no fer

\footnotetext{
${ }^{1}$ Ens sembla adient transcriure unes paraules de Torres Nebrera que trasllueixen el desconeixement en què ha viscut immersa, fins no fa gaire, l'obra d'aquesta remarcable autora:

Hace años (1976, quizà) me golpeó con sorpresa -un libro por cinco duros en un puesto callejero- la prosa rica, excelente, de María Teresa León, recreándose en la soledad iluminada de Jimena. No oculto que fue un descubrimiento que inmediatamente comuniqué a mis alumnos. ¿María Teresa León? Apenas se hablaba de ella, si es que algo se decía en los manuales al uso. Apenas su nombre en los catàlogos. Todavía patrimonio del exilio. (Nebrera 1987:11)
} 
referència a la figura de Rafael Alberti, a qui León va estar unida biogràficament i sentimental. A banda de la seua trajectòria literària, Maria Teresa León va atènyer gran protagonisme durant la guerra civil espanyola ja que, com és ben conegut, va ser artífex de l'evacuació dels quadres del Prado i de les guerrillas del teatro, sempre fent mostra d'una gran preocupació per la cultura proletària en aquells moments de màxima urgència. ${ }^{2}$ De Mercè Rodoreda, que va nàixer a Barcelona el 1908, es considera que és, sens dubte, l'escriptora contemporània que més projecció internacional ha donat a la literatura catalana del segle $\mathrm{XX} .^{3}$

Però, si una experiència ha marcat l'escriptura d'ambdues dones, aquesta és, clarament, la de l'exili. Una experiència considerada com a traumàtica no solament per l'allunyament espacial de la terra, de la cultura i de les gens sentides com a pròpies per l’individu, sinó també pel procés de no comunicació i d’aïllament que implica.

Va ser el 6 de març del 1939 que María Teresa León va emprendre el camí de l'exili acompanyada de Rafael Alberti. Diversos territoris europeus i del sud d'Amèrica van ser l'escenari del desterrament de la parella de literats que, finalment, culminà en terres mexicanes els trenta-vuit anys d'allunyament. L'exili de Mercè Rodoreda començà com el de León, amb aquell sentiment de transitorietat que comporta l'inici d'una aventura, en aquest cas iniciada el 23 de gener del mateix any 39. La història és força coneguda, no volà en avioneta -com María Teresa León- cap a terres alienes, sinó que muntada en un autobús que evacuava intel·lectuals catalans es dirigí cap a la frontera francesa per establir-se a Roissy-en-Brie, a pocs quilòmetres de París. Posteriorment, el seu exili pot considerar-se de poc normal, si és possible usar aquest adjectiu per a qualificar una situació que transcendeix no solament els límits de la quotidianitat sinó també la frontera d'allò que és esperable i desitjable. Després d'un temps d'estada a Roissy-enBrie, molts dels intel-lectuals que s'hostatjaven amb Rodoreda van decidir dirigir-se a terres americanes, mentre que l'autora i Armand Obiols es decantaren per romandre a Europa; així, Bordeux i Ginebra, foren alguns dels escenaris de l'exili de Rodoreda qui, malgrat tot i transcorreguts deu anys d'absència, viatjà en ocasions diverses a Catalunya,

\footnotetext{
${ }^{2}$ Vegeu Gregorio Torres Nebrera (2003), “Introducción” a María Teresa León, Fábulas del tiempo amargo y otros relatos, Madrid, Cátedra, pàg. 11.

${ }^{3}$ Vegeu Josep A. Fluixà (1997), "Introducció" a Mercè Rodoreda, La Plaça del Diamant, Alzira, Bromera, pàg. 7 .
} 
fet que li permeté el contacte esporàdic amb la família i amb aquells que formaven part de món literari català.

És difícil, en poques línies, resumir una experiència d’aquesta mena; tampoc no és la intenció d'aquest estudi fer-ho més enllà d'establir punts de contacte entre ambdues autores que, ben mirat, d’antuvi només tenien en comú el fet de ser dones dedicades a l’àmbit de la literatura en una Espanya que, tot just, començava a acceptar el seu accés en el món intel·lectual. A aquesta circumstància cal afegir, doncs, que ambdues resultaren exiliades a causa de l’opció cultural o de la ideologia política que ostentaven i que, ambdues també, foren víctimes del sentiment de desarrelament propiciat per l'exili; un sentiment que d'una manera o altra es reflectí en la seua escriptura. En aquest sentit diu Edward Said que l'exili, la immigració o el fet de creuar fronteres són experiències que ens ofereixen noves formes narratives. ${ }^{4} \mathrm{D}$ 'altra banda, tot i que sovint s'ha valorat de forma encertada, que la situació dels exiliats catalans suposava una pèrdua de més magnitud que la de la resta d'expatriats peninsulars -afirmació clarament sustentada en la impossibilitat d'escriure o parlar la pròpia llengua-, el fet de comparar les escriptures d'aquestes dues autores ens donarà compte d'un mateix sentiment de desarrelament que desembocarà en la creació de personatges marginals. ${ }^{5}$

Pot considerar-se que Memoria de la melancolía (Buenos Aires, Losada, 1970) és l'obra clau de María Teresa León en l'exili. L’autora se sentí impel·lida a escriure-la quan s’adonà que una malaltia esborrava de mica en mica justament això, la seua memòria; l'escriptura, com no, fou la manera que trobà al seu abast per a preservar-la. Així, en aquest cas, com en tants d'altres, els llibres de memòries s'erigeixen com a documents impagables per a reconstruir ja siga la vida, els pensaments o els sentiments de la generació que formà part de l'exili republicà. Contràriament a León, Rodoreda no se sentí en cap moment atreta per l'escriptura d'unes memòries; opinava que la seua vida íntima li pertanyia només a ella:

Si tingués la intenció d'escriure autobiogràficament, escriuria les meves memòries, però per escriure les meves memòries hauria d'interessar-me jo (jo no m’interesso gens). No m'agrada

\footnotetext{
${ }^{4}$ Vegeu Edward Said, “Representing the Colonized, Antropology's Interlocutors”, Critical Inquiry, 15 (1989), pàg. 205-225.

${ }^{5}$ Deia Rafael Tasis el 1939 en l'article que portava com a títol “Catalunya se’n va”: «Nosaltres, els catalans, ho hem perdut tot», referint-se al fet que l'enfonsament de la República suposava la mort del nostre esperit i del nostre idioma.
} 
parlar de la meva vida. La meva vida íntima és meva i, en principi, no m’interessa. Fujo d'entristirme i emocionar-me. D’un escriptor, el que és important és la seva obra. ${ }^{6}$

Potser per aquest motiu, Rodoreda centrà l'atenció en la creació de mons que, tot i pertànyer a l'imaginari, reflectien i reflecteixen encara indefugiblement la concepció de la realitat que copsava l'escriptora. Els contes, tant en una autora com en l'altra, representen la forma d'expressar aquells sentiments suscitats per una realitat que traspua la malenconia i la buidor ocasionades per les vivències d'un exili indefinit; també representen, però, el mitjà per a creuar i crear diversitat de codis culturals i de mons fantàstics que, en definitiva, remetran el lector a les experiències físiques i mentals de les autores. Ara com ara, doncs, ens interessa analitzar la narrativa breu que León i Rodoreda van redactar en la seua condició de dones exiliades. L'apropament a alguns dels seus contes i dels personatges que els poblen ens ajudarà a establir de quina manera la precària situació anímica de les autores es reflecteix en l'escriptura i en confirmarà el poder catàrtic com a instrument que permet exterioritzar els desequilibris interns. Pel que fa a la tria de l'escriptura breu durant aquest període convuls de la seua vida, Carme Arnau afirma de Mercè Rodoreda que:

Durant els anys de la segona Guerra Mundial, Mercè Rodoreda es va veure abocada a una situació de precarietat i d'angoixa, en la qual l'escriptura era difícil, per no dir impossible. [...] l'escriptura de la novel-la resultava impossible per la complexitat d'aquest gènere, un gènere que demanava un esforç intens i, sobretot, continuïtat. Molta dedicació. En canvi, l'avantatge del conte n’és la brevetat, que vol dir més rapidesa en l’execució. (Arnau 2000: 13)

La mateixa Rodoreda en escriure a la seua amiga Anna Murià es fa ressò d'aquesta situació:

Com no tinc temps per fer res que no sigui massa llarg, ni que m’absorbeixi massa, penso dedicarme una temporada llarga [...] a fer contes i a fer-los seriosament. [...] No, no faig ni faré novel·la per ara. No tinc temps. Un conte es pot escriure relativament de pressa. Le temps d'un sein nu entre deux chemises. La novel·la és massa absorbent. A més he descobert que el conte és un gran gènere.

Malgrat tot, Mercè Rodoreda ja va fer incursions en el gènere durant l’època de la guerra; es tracta de contes apareguts en publicacions com Companya, Moments, Revista de Catalunya o Meridià; són obres de vàlua literària menor que responen a l’intent de

\footnotetext{
${ }^{6}$ Vegeu Mercè Rodoreda, Autoretrat, a cura de Mònica Miró i d'Abraham Mohino, Angle Editorial, Barcelona, 2008, pàg. 258.

${ }^{7}$ Mercè Rodoreda, Cartes a l’Anna Murià 1939-1956, Barcelona, La Sal.
} 
reforçar els ànims de les tropes republicanes. Fruit de les vivències a l'exili ${ }^{8}$ resultà el volum Vint-i-dos contes, publicat tardanament el 1958, del qual Carme Arnau (1979: 99) destaca tres eixos temàtics «pessimisme, tristesa i crueltat». El recull publicat l'any 1967, La meva Cristina i altres contes, suposa -segons aquesta mateixa estudiosa- la major contribució de l'autora al gènere i coincideix amb un allunyament progressiu de la realitat:

El que podria caracteritzar l'evolució de la prosa rodorediana és un procés de sàvia literaturització d'una sèrie de temes i d'obsessions vitals, de complexos i culpes, profundament lligats a la seva vida, i per això mateix, sempre convincents, sempre versemblants... però progressivament allunyats de la biografia directa i personal de l'autora. ( Arnau 1991:28)

Als darrers anys de la seua trajectòria vital pertanyen els volums Semblava de seda $i$ altres contes (1978), Viatges i flors (1980) i Un café i altres narracions (1999), volum amb valor documental, on es recullen narracions disperses de Rodoreda apareguts en diaris i revistes. ${ }^{9}$

Si bé, com hem comentat, la inclinació contística de l'autora catalana a l'exili sembla motivada per raons domèstiques, com la manca de temps, -ja que Mercè Rodoreda hagué de dedicar-se a la costura per tal de poder sobreviure econòmicament-, també reconeix la passió que exerceix sobre ella aquest gènere:

Tinc una cinquantena de contes en la cartera i em penso que bé n’hi haurà mitja dotzena de bons entre tots plegats. Ara faig un estudi a fons dels contistes americans. Els que més admiro són Steinbeck, Faulkner, junt amb el meu amor que és K. Mansfield [...] És difícil trobar el secret d'aquesta força d'expressió. Si un dia el trobo... ${ }^{10}$

És més que evident que aquest secret el va trobar, potser per aquest motiu ja no es va apartar del conreu del gènere fins a la fi de la seua trajectòria literària i vital. Pel que fa a María Teresa León, l’afició pels contes naix gairebé al mateix temps que la seua vocació literària. Així, Cuentos para soñar del 1928 va ser el primer llibre de l’autora, obra en la qual ja es deixa entreveure el tarannà progressista que la caracteritzaria al

\footnotetext{
${ }^{8}$ Exili durant el qual l’autora residí a Llemotges (1940), Bordeus (1945), París (1946) i Ginebra (1954).

${ }^{9}$ Es tracta del volum editat per l'Institut d'Estudis Catalans a cura de Carme Arnau, en la introducció del qual la curadora informa que es proposa d'aplegar les narracions de Mercè Rodoreda que no aparegueren en els reculls anteriors.

${ }^{10}$ Cartes a l'Anna Murià 1939-1956, op.cit., pàg. 73-74. Un apropament a la influència que Katherine Mansfield va exercir sobre Mercè Rodoreda podeu trobar-lo en l'estudi d'Enric Balaguer "Katherine Mansfield i Mercè Rodoreda (episodis domèstics, servitud dels detalls)”, dins de Catalan Review, vol. IX, 1995, pàg. 21-31.
} 
llarg de la seua producció literària. ${ }^{11}$ Es tracta d'un llibre de contes dirigit a infants on María Teresa León fa una barreja de modernitat i de tradició contística universal (Grimm, Perrault, Shakespeare, Macterlink, etc). ${ }^{12}$ Després vingué el recull titulat $L a$ bella del mal amor editat el 1930, que remet a motius literaris del Romancer com ara el de la malcasada o la malmaridada. El 1934 León reprengué la publicació contística amb el recull Rosa-Fría patinadora de la Luna, el més reeditat de tots; es tracta novament de contes per a infants, tot i que aquesta vegada remeten a una cosmovisió moderna amb influència de la pintura de Picasso o de Miró entre d'altres. ${ }^{13}$ El volum Cuentos de la Espanya actual aparegué el 1936; molts d'aquests contes van ser redactats a Mèxic, al llarg d'una obligada estada dels Alberti documentada per Robert Marrast l'any 1984. Els Cuentos de la Espanya actual testimonien les lluites de classes que protagonitzaren el Bienni Negre, dins del marc històric dels successos asturians de l'any 1934. En aquest moment, la prosa de María Teresa León esdevé altament crítica amb la societat del moment i és lícit afirmar que s’insereix dins d'una literatura social revolucionària inscrita en la ideologia comunista (Torres Nebrera 2003: 48-61).

La col·lecció Moriràs lejos... va ser editada a l'exili. Dels divuit contes que formen part del recull, només vuit en són nous, la resta ja havien aparegut en Cuentos de la Espanya actual. Es tracta d'històries fruit de vivències de l'autora, particularment la guerra i de l'exili, cosa que, en ocasions, la fa retornar a la infantessa o a l'adolescència per a poder reviure sentiments d'aquelles etapes de la vida, tot recreant-se sovint en una sensació de desterrament sense possibilitat de retorn molt típica dels exiliats. Las peregrinaciones de Teresa, recull publicat a Buenos Aires l'any 1950, suposa una recerca en la memòria personal i recrea personatges que, sovint, poden confondre's amb la mateixa autora, plens de força de voluntat i de coratge.

A l’últim, Fábulas del tiempo amargo, editada a Mèxic el 1962, són relats que expressen la riquesa d’un món interior bastit mitjançant el devenir de la història personal, però també a través de les vivències de la col·lectivitat, d'una col·lectivitat

\footnotetext{
${ }^{11}$ Algunes de les històries que conformen aquest recull de contes ja havien aparegut, fins i tot uns anys abans, en una primera versió, al Diario de Burgos.

${ }^{12}$ El llibre s'inicia amb una curiosa nota de María Goyri que exalta la condició de mare de l'autora i que diu així: «Una madre, dotada de temperamento de artista, como la autora de esta obra, tiene mucho adelantado para adueñarse del alma del niño, y hacerle soñar con sus relatos, y más si, como aquí ocurre, se apoya en los cuentos tradicionales, ese tesoro que han ido acumulando los siglos» (Goyri 1928: 5-6).

${ }^{13}$ Podeu ampliar el tema amb el treball de Carmen Bravo Villasante, "María Teresa León, mujer de letras (Los cuentos de María Teresa León)”, María Teresa León, Junta de Castilla y León, 1987, pàg. 13-22.
} 
convertida en exiliada i, com a tal, sempre anhelant un retorn que per a alguns mai no arribarà. Es tracta d'històries que s'adiuen amb una estètica surrealista i que atenyen, fins i tot, la qualitat de prosa lírica.

Queda constància, doncs, de l'amplitud i varietat de la producció contística d'aquestes autores; comparar-ne temàtiques, continguts i formes resultaria una tasca massa ingent per a aquestes pàgines, en les quals ens veiem obligats a oferir-ne simplement un tast que obri les línies d’un futur aprofundiment en la matèria. Pel que fa a la narrativa breu de l'exili de María Teresa León, hem triat dos contes, un escrit a l’inici de l'exili de l'autora i l'altre redactat gairebé vint anys després i pertanyent al volum Fábulas del tiempo amargo. En aquest cas, la tria de dues narracions allunyades en el temps respon al desig d'observar l'evolució de l'estat d'ànim de l'autora durant la seua estada a l'exili, reflectida de manera contundent en l'expressió de la seua creació literària.

Començarem per "El perfume de mi madre era el heliotropo" narració que s'emmarca dins la colecció Moriràs lejos ... de l'any 42. Es tracta d'un conte amb un alt contingut líric, com és habitual en María Teresa León. Resulta remarcable com l'apropament a vivències viscudes durant la infantesa serveix a l'autora per a establir nexes amb l'experiència de l'exili. La història s'articula en dos moments diferents; durant el primer la protagonista evoca episodis de la seua infantesa relacionats amb l'entorn familiar més immediat. Es tracta del record de l'avi, de la mare -sovint massa ocupada amb nombrosos compromisos socials- i, també, del pare, a qui se li coneixen relacions extramatrimonials. Aquests records resulten clarament autobiogràfics, relacionables amb la infantesa que l’escriptora visqué a Burgos. ${ }^{14}$ Així, Isabel, la protagonista, és una nena que viu en un món fosc, envoltada pels records de la mare morta, l’aroma de la qual encara es troba pertot i desencadena l’intens procés d’evocació que bastirà l'entramat de la primera part del relat:

Pero el perfume del heliotropo le cosquillea femeninamente en la nariz, trayéndole un recuerdo. Ve tan dentro la imagen, que se echa a soñar, mirando la linterna mágica de su memoria y se

\footnotetext{
${ }^{14}$ Gregorio Torres Nebrera (1996: 99) fa al·lusió al suggeriment d’aquestes experiències autobiogràfiques i observa com en les primeres pàgines de Memòria de la melancolía es reprodueix un univers personal que presenta indubtables connexions amb el personatge de la història que ens ocupa, al títol de la qual es fa una referència directa amb aquestes paraules: «Detrás de ese olor quedaba el de mi madre, heliotropo o violeta».
} 
tumba sobre un montón de trajes, envuelta en las ondas del heliotropo que vienen a romperse hasta su carne oscura, bañándola de un vago tejido de sueños. ${ }^{15}$

És d'aquesta manera com el món del record, del passat, representat per la figura de la mare, s’erigeix com a símbol de la terra perduda; mentre que la Tata María, que s’ha fet càrrec d'Isabel, substituirà la mare biològica i serà la càlida metàfora de l'indret que acull l'exiliat: "La Tata María la mantiene apretada contra el pecho. «Adiós, di adiós a mamá.» Pero la niña no ha dicho adiós, sino que al esconder su cara en el hombro maternal de su Tata, ha pensado por primera vez: «Mi madre es ésta.»»16

Resulta remarcable observar com la història parteix d'una escena quotidiana. Isabel, la protagonista, juga al bell mig del camp, com ho fa habitualment; juga a matar ocells amb una ona, l'un darrere l'altre, del matí al vespre. La cruesa amb què la infant porta a terme l'acció ens permet transcendir la referencialitat de la imatge per a endinsar-nos en el valor simbòlic d'allò narrat. Isabel sacrifica ocells, ratolins, grills, papallones, espia el dolor que senten fins a l'instant de la mort, punt en què els petits animals deixen d'interessar-li. És el sacrifici del petit, de l'humil, en favor del poderós, símbol del dolor que ella mateixa s’ha vist obligada a patir, amb la mare morta i un món bastit gairebé només de records que la mantenen angoixada.

La natura juga un paper important; és l'espai on es desenvolupa la història i en el qual la protagonista viu la transformació fisiològica d'infant a dona. Els arbres, els animals i, sobretot, l'aigua del riu on s'endinsa Isabel, intervenen com a personatges i esdevenen testimoni d'aquesta escena que conformarà la segona part de la història. Així, malgrat el dolor causat per la pèrdua forçada d'allò que Isabel més estima, un bany simbòlicament purificador en el mateix riu on s'havia banyat la mare, ompli el relat de vida. Isabel menstrua per primera vegada i la imatge de fecunditat de l'adolescent s'erigeix com a símbol d'unió entre mare i filla. La comunió amb la natura permet el renaixement d'Isabel en una terra on potser un dia ella també serà mare. Aquesta imatge ens permet realitzar una lectura en clau positiva de l'exili: la malaurada pèrdua de la terra pròpia no impedirà, malgrat tot, que la vida continue per a la protagonista, perquè,

\footnotetext{
${ }^{15}$ María Teresa León, Fábulas del tiempo amargo y otros relatos, Edició de Gregorio Torres Nebrera, Madrid, Càtedra, 2003, pàg. 235. A partir d'aquest moment, les cites referents a l’obra de María Teresa León faran referència a aquesta edició.

${ }^{16}$ María Teresa León, op. cit., pàg. 236.
} 
com diu la història en el seu inici «Ella era su patria», l'autosuficiència del personatge com la de la mateixa autora- s’imposa i esdevé la recompensa pel sacrifici patit.

D’aquest relat s’ha de destacar encara la intervenció de Salvador. Salvador és amic d'Isabel i, com la mateixa protagonista, es tracta d'un personatge clarament relacionat amb la infantesa de l'autora. Lluny, però, d'interessar-nos en aquest moment l'aspecte biogràfic del personatge, el que volem remarcar és el seu caràcter marginal, humil i sotmés a la voluntat d'una Isabel que gaudeix demostrant el seu tarannà tirànic amb el més dèbil. És justament aquesta crueltat manifesta en la protagonista la que la converteix, a ella també, en un ésser instal-lat en la marginalitat dels sentiment humans. ${ }^{17}$

Divuit anys més tard, l’escriptura de María Teresa León és més hermètica, més simbòlica i d’interpretació més difícil. Propera a un surrealisme tardà (Nebrera 2003: 83), la narració “Comed, comed que ya estoy invitada”-pertanyent a la col·lecció Fábulas del tiempo amargo-, n’és un clar exemple. ${ }^{18}$ Com en una autèntica faula, el conte s'emmarca novament en un paisatge natural, en aquest cas dins d'un bosc; la protagonista es desdobla en un cérvola blanca que ha presentat lluita contra els caçadors però que, finalment, s’ha de deixar immolar. Aquest desdoblament comporta la confusió en el lector, que no sap ben bé qui parla: l'ésser humà o l'animal. El relat ofereix una transgressió de caire fantàstic que trenca amb l'assignació d'una identitat determinada al discurs. És així com assistim a la metamorfosi, a la transformació de l’individu que, enfrontat al fort i esdevingut un ésser marginal, es troba davant la impossibilitat del retorn. La presentació d’una circumstància fantàstica -la transgressió del món humà que permet a la protagonista situar-se en un simbòlic regne animal- serveix a María Teresa León per a deixar constància del seu estat anímic, víctima de la metamorfosi -d’ençà l’inici del seu exili i d'una estrangeria constant.

\footnotetext{
${ }^{17}$ És també Torres Nebrera (1996: 100) qui remarca la relació de Salvador amb l'experiència personal de l'autora. Torres Nebrera cita un fragment de Memoria de la melancolia on es justifica aquesta relació, fragment que aquí transcric en part: «Fue entonces cuando apareció el chico tonto que jugava con ella tan guapo, tan rubio, tan esbelto. Trece años perdidos porque era tonto. [...] La niña se frotó los labios cuando apareció Salvador. Le traía un jilguero. La niña no miró el pájaro sino la boca entreabierta de dientes impecables y se abrazó a su cuello y le besó en los labios»

${ }^{18}$ De les històries que formen part d'aquest conjunt de relats, Torres Nebrera (1996: 112) afirma que: «son historias de un tiempo histórico y existencialmente dolorido, trágico, cruzado de sangre, exilios y soledades»
} 
La dona-cérvola, vençuda, observa el seu propi sacrifici, mentre la mare i el germà, seuen a taula amb els vencedors. L'autora ja no permet que els seus personatges es redimeixen establint ponts amb el record ni mantenint la confiança en el futur. «Iba a desangrarme», són les paraules mancades d'esperança que encapçalen el relat. El futur ha arribat i s'ha presentat ple de sang, però no d'aquella sang virginal que cloïa el primer dels relats analitzat, sinó de la sang fruit dels odis, de les venjances i de les desavinences suscitades per la guerra: «un solo latido me dijo que no hay mayor desconsuelo que perder, gota a gota, la sangre sobre la tierra que nunca jamás volveremos a pisar...». ${ }^{19}$

El dolor s'ensenyoreix del relat; un dolor que s’intensifica i transmet mitjançant la primera persona emprada per la narradora-protagonista. És el dolor dels vençuts, de les víctimes, dels captius, dels sacrificats. La cérvola blanca, símbol de la puresa d’ideals, ha lluitat i ha perdut, ara serà devorada i la seua carn es convertirà en l'àpat dels vencedors: «La grasa del convite chillaba, dispuesta, encendidas las luces del banquete sobre la mesa, que sin comprender, había visto cómo extendían, para trinchar sobre ella, el sueño extraño de los libres» (pàg. 310). ${ }^{20}$

Són diversos els temes que magistralment s'entrecreuen en aquest breu relat; la guerra, l'exili, els odis familiars, la tragèdia dels vençuts contraposada a la joia dels vencedors. Però també, curiosament, el de la víctima dona que resta, més sovint que l’home, sense ningú que l'escolte: «La cabeza, desdeñada por todos, ha quedado en mitad de la fuente. ¡Esa soy yo!, les grito. Como nadie me escucha, agarro mi cabeza y desaparezco del salón del banquete sin dar a nadie cuenta de mis actos» (pàg. 314). ${ }^{21}$

Pel que fa a Mercè Rodoreda, ja hem comentat adés que tant l'exili que visqué com les raons que la menaren a fer narrativa breu, foren prou diferents a les de Maria Teresa León; malgrat tot, les protagonistes i les circumstàncies que ens ofereixen els seus relats presenten certs punts en comú amb els de María Teresa León.

\footnotetext{
${ }^{19}$ María Teresa León, op. cit., pàg. 311.

${ }^{20}$ Es poden establir analogies amb el festí de mort de Gorgo, en El Adefesio: «El festín puede comenzar».

${ }^{21}$ La dona, com a víctima, com a personatge marginal, és un tema recurrent en els contes de María Teresa León. El motiu de la mal casada es repeteix en el volum La bella del mal amor; d'altra banda, Las peregrinaciones de Teresa es fan ressò de les circumstàncies adverses que els toca viure a tot tipus de dones, sovint abnegades, resignades i mancades d'una instrucció que els permeta sortir de la marginalitat en què es veuen immerses.
} 
Ja hem vist que, tot i que l'autora catalana va escriure la majoria dels contes durant la primera part de l'exili, no fou fins l'any 1958 que se'n publicà el primer volum, Vint-idos contes, premi Víctor Català de l'any 1957. Deu anys més tard, el 1967, n’apareixia el segon recull, sota el títol La meva Cristina i altres contes. Aquest recull coincideix literàriament parlant, amb un allunyament progressiu de la realitat per part de l'autora. Des d'aquest punt de vista pot establir-se un paral-lelisme entre la literatura de Rodoreda i la de León, ja que ambdues tendeixen cap a una mena de surrealisme que materialitza les pròpies obsessions.

En aquest sentit, afirma Neus Carbonell amb referència a la narrativa breu de Rodoreda que:

Cabe afirmar que en Rodoreda se pasa de la pesadilla al sueño, de ficcionalizar una realidad insoportable a imaginar una realidad extraña o maravillosa. Estos mundos alternativos en Rodoreda desafían la experiencia de la vida moderna reescribiendo, y por tanto controlando, la pérdida de centro que supone vivir en los márgenes de un exilio que no se percibe como una pérdida absoluta sino como la experiencia de vivir más allá de la frontera. (Carbonell 1998: 582)

De la mateixa manera que León, Rodoreda apel·la a la pròpia infantesa especialment en la creació d'algun dels personatges que donen vida a la narrativa breu corresponent als primers temps de l'exili. Com afirma Carme Arnau (1999: 16) «La infantesa va ser per a ella una font permanent i d'inspiració, una part important del seu ric imaginari». D’aquesta manera les experiències vitals de l'autora es recreen mitjançant l'escriptura, tot i que Rodoreda -gairebé amb el conte que esmentem a continuació com a única excepció- no intenta, en línies generals, reconstruir esdeveniments viscuts sinó reelaborar els sentiments o les sensacions que aquests esdeveniments li han produït fins a convertir-la en el que és.

Un exemple paradigmàtic en què la infantesa de l'escriptora queda plasmada en un dels seus relats, és el conte titulat "El bany", pertanyent al primer dels reculls publicats per Rodoreda. En aquesta història la protagonista rep el nom de Mercè i vesteix igual que l'autora en una fotografia de l'època. Diu el conte: «Duia un vestit de musselina carmí amb una peça de musselina blanca; al pit un pom de miosotis retenia un grup de tavelles. 
Mitjons blancs, sabates de xarol negre i un llaç del mateix color del vestit, com una papallona damunt dels cabells». ${ }^{22}$

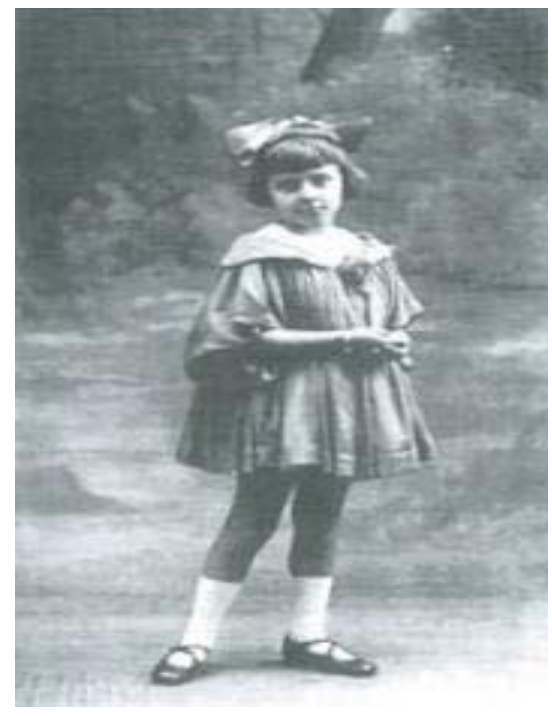

L’observació de la fotografia no permet dubtar sobre el fet que, en aquest cas, la protagonista de la narració literària es correspon amb l'autora. A més, l'anècdota que serveix d'entramat al conte és, així mateix, una anècdota viscuda per Mercè Rodoreda qui, el 1913, debutà com a actriu al teatre Torrent de les Flors. L'avi Gurguí, en recompensa, li comprà una nina ben grossa que l’autora rememora en aquesta narració, que assoleix així un cert tarannà autobiogràfic. A diferència del que s’esdevé en el conte de León, on la mare de la protagonista és la figura que pren relleu, en la història de Mercè Rodoreda l'avi és el vincle familiar que l'autora recorda de forma més entranyable:

Eren inseparables. A ell no li havia sortit mai un reny dels llavis per a aquella criatura més aviat lletja i esquifida, turbulenta com una ventada de març. El pentinava cada vespre. Abans d'anar al llit s'asseia sobre la taula del menjador amb una pinta i unes quantes cintes. Si estava distret, el cridava: «Avi! Vine, que et pentinaré». ${ }^{23}$

En aquesta història, Rodoreda no busca establir punts d'unió entre el passat i el present, pretén tan sols recordar. Potser per això “«El bany» mostra una infantesa amable amb amics i família, una infantesa que traspua calidesa i que es contraposa a una gran

\footnotetext{
${ }^{22}$ Mercè Rodoreda, “El bany”, Tots els contes, Edicions, 62, Barcelona, 2008, pàg. 156. A partir d'aquest moment, les citacions dels contes de l'autora faran referència a aquesta edició. La fotografia pertany a $D e$ foc i de seda. Àlbum biogràfic de Mercè Rodoreda, a cura de Marta Nadal, editat l'any 2000 per Edicions 62, la Fundació Mercè Rodoreda i l’Institut d'Estudis Catalans.

${ }^{23}$ Mercè Rodoreda, op.cit., pàg. 157.
} 
quantitat de relats on predomina la soledat i, fins i tot, la marginació d'uns personatges principals que exhibeixen personalitats aclaparades per un egocentrisme que els resulta devastado” (ESCANDELL; MARCILLAS 2008)

"La salamandra”, narració inclosa en La meva Cristina i altres contes narra la història d’una dona que manté una relació adúltera amb un home casat, per aquesta raó és rebutjada per la comunitat, acusada de bruixa i cremada en una foguera. Mentre crema, es transforma en salamandra i és perseguida per la dona del que havia sigut el seu amant i pels infants del poble. Finalment tres anguiles se li mengen una mà:

les anguiles jugaven amb aquell trosset de mi i el deixaven i el tornaven a agafar i la maneta anava d'una anguila a l'altra, giravoltant com una fulla petita, amb els dits separats. I jo era, a dues bandes: entre el llot amb les anguiles i una mica en un món que no acabava de morir-se ... Fins que les anguiles es van cansar i l'ombra va xuclar la maneta. Una ombra espessa, que estenia a poc a poc la pols de l'aigua, dies i dies, en aquell racó de llot, entre arrels d'herba i de salze que tenien set $\mathrm{i}$ bevien allà des de sempre. ${ }^{24}$

De la mateixa manera que en el cas de la narració de María Teresa León, “Comed, comed que ya estoy invitada”, "La salamandra” és una història narrada en primera persona, amb la qual cosa la implicació del lector i la profusió de l'anàlisi psicològica augmenten. Aquesta circumstància provoca un sentiment que s'instal·la entre la intensitat i l'angoixa, amarades ambdues d’una condensació lírica que ben bé pot aplicar-se al conte de l'escriptora burgalesa. Observem també un paral-lelisme entre ambdues històries pel que fa al locus amoenus; la natura s’erigeix com a personatge, intervé en la història amb un paper de caire simbòlic que vaticina esdeveniments. En Rodoreda “l'aigua s’anava fent trista i els arbres que s’enfilaven cap a dalt del turó es tornaven negres a poc a poc” (pàg. 260); en León "sucede todo esto el día en que el encantamiento del sol hace del bosque nuestra casa más inocente. El agua antigua lo ha cambiado todo en abudante despensa” (pàg. 309). En ambdues autores, el bosc esdevé un espai narratiu opressiu en el qual la protagonista es converteix en víctima del dolor i resta mutilada per sempre més.

En aquest sentit, no es pot obviar, en Rodoreda igual que en León, la metamorfosi que pateix la protagonista. Convertida en rèptil, en "La salamandra", la dona ha de conformar-se amb viure en la marginalitat, una marginalitat que es pot interpretar com

\footnotetext{
${ }^{24}$ Mercè Rodoreda, op.cit., pàg.267.
} 
a doble: la que ha de patir la dona considerada com a promiscua per la societat i aquella marginalitat a què es veu sotmés l'expulsat de la pròpia terra. La relació amb l'exili resulta, doncs, patent.

Com a conseqüència de la transgressió de les normes imposades per la societat, l'individu es veu condemnat a viure agonitzant entre dos mons, perquè una part d'ell sempre roman al lloc del qual ha estat expulsat. El simbolisme i l'allunyament de la realitat són les eines que serveixen a Rodoreda per a bastir una història enigmàtica però també per a expressar el sentiment de desarrelament propi dels exiliats.

Rodoreda i León, són dues exiliades que literaturitzen aquesta experiència. Ambdues senten la necessitat d'establir vincles amb allò que els ha estat arravatat i l'escriptura dels records d'infantesa és el que les ajuda a retrobar-se amb la identitat perduda en una terra aliena. Amb el pas del temps, també ambdues evolucionen cap a una narrativa de caire més simbòlic i enigmàtic; escriptura on les protagonistes són sovint dones que viuen l'experiència de l'exili condicionades justament pel fet de ser-ho; així la donacèrvol, del relat de Maria Teresa León, símbol de la innocència i de la indefensió, alça la veu però no és escoltada, mentre que la sargantana del conte de Rodoreda resta mutilada i rebutjada per la societat per sempre més.

Tant l'escriptora burgalesa com la catalana parteixen d'històries d'infantesa en què un narrador omniscient deixa constància de la distància -temporal i espacial- que existeix entre el protagonista i l'autor. Tanmateix, amb el decurs del temps, ambdues arriben a la psiconarració en primera persona i la usen com a eina que les ajuda a explicar la pròpia emotivitat, les angoixes vitals que les assetgen i que dificulten la seua evolució com a integrants d'una societat que les margina massa sovint. Com les mateixes escriptores, els personatges dels seus relats són dones exiliades que s’han vist obligades a patir una metamorfosi en una terra en la qual sempre se sentiran estrangeres.

\section{Bibliografia}

Arnau, Carme. 2000. Memòria i ficció en l'obra de Mercè Rodoreda, Barcelona, Fundació Mercè Rodoreda.

Balaguer, Enric. 1995. "Katherine Mansfield i Mercè Rodoreda (Episodis domèstics, servitud dels detalls)”, Catalan Review vol. IX, núm 1, pàg. 21-31. 
Bravo Villasante, Carmen. 1987. "María Teresa León, mujer de letras (Los cuentos de María Teresa León)”, María Teresa León, Junta de Castilla y León, pàg. 13-22.

Carbonell, Neus. 1998. “Exilio, escritura y el género fantàstico en los cuentos de Mercè Rodoreda”, El exilio literario español de 1939, Barcelona, Gexel, pàg. 579-585.

Escandell, Dari; Marcillas, Isabel. 2008. “Els límits de l’espai autobiogràfic en la narrativa breu de Mercè Rodoreda”, comunicació presentada en la jornada d'estudi “Le temps historique et les espaces urbains dans l'oeuvre de Mercè Rodoreda”, celebrada el 2 de juny de 2008 al Céntre d'Études Catalanes de la Université Paris-Sorbonne Paris IV, consultable en http://rua.ua.es/dspace/handle/10045/7810

Fluixà, Josep A.. 1997. “Introducció” a Mercè Rodoreda, La Plaça del Diamant, Alzira, Bromera, pàg. 7 .

Goyri, Maria. 1998. Introducció a Cuentos para soñar, Burgos, Editorial Hijos de Santiago Rodríguez, 1928; reedición facsimilar del Ayuntamiento de Burgos, con estudio preliminar de Juan Carlos Estébanez Gil, pàg. 5-6.

León, María Teresa. 1998. Cuentos para soñar, Burgos, Editorial Hijos de Santiago Rodríguez, 1928; reedición facsimilar del Ayuntamiento de Burgos, con estudio preliminar de Juan Carlos Estébanez Gil.

León, María Teresa. 2003. Fábulas del tiempo amargo y otros relatos, Madrid, Cátedra. Marrast, Robert. 1984. Rafael Alberti en México, Santander, La Isla de los Ratones.

Nadal, Marta. 2000. De foc i de seda. Àlbum biogràfic de Mercè Rodoreda, Barcelona, Edicions 62-Fundació Mercè Rodoreda-Institut d’Estudis Catalans.

Rodoreda, Mercè. 1985. Cartes a l’Anna Murià 1939-1956, Barcelona, La Sal.

Rodoreda, Mercè. 1999. Un cafè i altres narracions, a cura de Carme Arnau, Barcelona, IEC.

Rodoreda, Mercè. 2008. Tots els contes, Barcelona, Edicions 62.

Rodoreda, Mercè. 2008. Autoretrat, a cura de Mònica Miró i d’Abraham Mohino, Barcelona, Angle Editorial.

Said, Edward. 1989. "Representing the Colonized, Antropology's Interlocutors", Critical Inquiry 15, pàg. 205-225.

Tasis, Rafael. 1939. «Catalunya se’n va», Catalunya [Buenos Aires] 106, pàg.3.

Torres Nebrera, Gregorio. 1996. Los espacios de la memòria (La obra literaria de María Teresa León), Madrid, Ediciones de la Torre.

Torres Nebrera. 1987. La obra literaria de María Teresa León (autobiografía, biografías, novelas), Cáceres, Universidad de Extremadura. 